\title{
What do adult patients with congenital heart disease know about their disease, treatment, and prevention of complications? A call for structured patient education
}

\author{
P Moons, E De Volder, W Budts, S De Geest, J Elen, K Waeytens, M Gewillig
}

\begin{abstract}
Objective-To assess how much adults with congenital heart disease understand about their heart defect, its treatment, and the preventive measures necessary to avoid complications.

Design-Descriptive, cross sectional study.

Setting-Adult congenital heart disease programme in one tertiary care centre in Belgium. Patients-62 adults with congenital heart disease ( 47 men; 15 women), median age 23 years. Main outcome measures-Patients' knowledge was assessed during an outpatient visit using the Leuven knowledge questionnaire for congenital heart diseases, a 33 item instrument developed for this study.

Results-Patients had adequate knowledge ( $>80 \%$ correct answers) about their treatment, frequency of follow up, dental practices, occupational choices, appropriateness of oral contraceptives, and the risks of pregnancy. Knowledge about the name and anatomy of the heart defect, the possibility of recurrent episodes of endocarditis during their lifetime, and the appropriateness of different physical activities was moderate (50-80\% correct answers). There was poor understanding ( $<50 \%$ correct answers) about the reasons for follow up, the symptoms of deterioration of the heart disease, the definition, characteristics, and risk factors of endocarditis, the impact of smoking and alcohol on the heart disease, the hereditary nature of the condition, and the suitability of intrauterine devices as contraceptives.

Conclusions-Adults with congenital heart disease have important gaps in their knowledge about their condition. The results of this study can be used as a basis for developing or optimising structured educational interventions to enhance patients' health behaviour.

(Heart 2001;86:74-80)
\end{abstract}

Keywords: patient education; congenital heart disease; health behaviour

Congenital heart disease is in many cases a chronic disorder because of the residual effects and sequelae of corrective or palliative procedures. ${ }^{1}$ These patients are thus prone to complications such as atrial arrhythmias, bacterial endocarditis, congestive heart failure, or pulmonary vascular disease. ${ }^{2}$ To minimise the risk of complications and to enhance overall health status, patients are expected to adopt certain health behaviours, such as restricting severe physical activity, adhering to a prescribed regimen of drug treatment, or engaging in specific hygienic measures to prevent endocarditis.

It is recognised that knowledge about the disease and its treatment is a key factor in promoting good health behaviour. ${ }^{3}$ However, little is known about this in patients with congenital heart disease. There have been studies on the parents of children with congenital heart disease ${ }^{4-8}$ and to a lesser extend on adolescent $^{910}$ or adult patients, ${ }^{11-14}$ but these have focused predominantly on knowledge about the heart defect, previous and current treatment, and the definition, prevention, and prophylaxis of endocarditis. It is arguable that knowledge about physical and vocational activities, contraception, pregnancy, and heredity is also critical for optimal health behaviour in this population, ${ }^{15}{ }^{16}$ though these factors have not yet been studied.

Results of previous studies showed that $54-68 \%$ of the patients ${ }^{913}{ }^{14}$ were able to define or describe their heart defect. The definition of endocarditis and the measures necessary to prevent it were less well understood, with correct answers varying from $16 \%{ }^{13}$ to $50 \%{ }^{14}$ in adult patients. Between $78 \%$ and $96 \%$ of patients were aware of the need to take medicines before surgical or dental procedures, but only half of them knew that these medicines were antibiotics. ${ }^{691114}$ We conclude from these investigations that much needs to be done to improve patients' knowledge about their heart condition, and about endocarditis and its prevention.

As there are no published reports assessing all the areas of knowledge required for adequate health behaviour in people with congenital heart disease, we designed a study to assess adult patients' understanding of their disease, its treatment, and measures necessary to prevent complications.

\section{Methods}

STUDY POPULATION

In a descriptive, cross sectional study, we recruited literate, Dutch speaking adults $(\geqslant 18$ years) with congenital heart disease who 
attended the outpatient clinic of the University Hospitals of Leuven (Belgium) during a three month period. Informed consent was provided orally. Patients were excluded if this was their first visit to the outpatient clinic at our centre, if they had learning disabilities, if they were newly diagnosed as adults with an atrial septal defect, or had a patent foramen ovale discovered coincidentally after an unexplained cerebrovascular accident.

Seventy patients with congenital heart disease met the inclusion criteria. Two of them refused to participate in the study and six were not included because they were too emotionally distressed. The final sample thus consisted of 62 subjects ( $39 \%$ of the patients seen by the congenital cardiologist in this period). The most common reasons for non-inclusion were patients being under 18 years of age $(21.6 \%)$, having learning disabilities $(9.1 \%)$, having an atrial septal defect diagnosed at older age $(9.1 \%)$, or not having a congenital heart defect $(9.1 \%)$. This suggests that the sampling did not introduce bias by selecting only the most motivated or educated patients.

Table 1 summarises the demographic and clinical characteristics of the study sample. Forty seven patients were male $(75.8 \%)$ and 15 were female $(24.2 \%)$, with a median age of 23

Table 1 Demographic and clinical characteristics of 62 adult patients with congenital heart disease

\begin{tabular}{|c|c|c|}
\hline \multicolumn{3}{|l|}{ Variable } \\
\hline \multicolumn{3}{|l|}{ Sex } \\
\hline Male & 47 & $(75.8 \%)$ \\
\hline Female & 15 & $(24.2 \%)$ \\
\hline Median age (years) & 23 & $\left(Q_{1}=21 ; Q_{3}=28\right) ;$ range $18-46$ \\
\hline \multicolumn{3}{|l|}{ Civil state } \\
\hline Unmarried (living with parents) & 34 & $(54.8 \%)$ \\
\hline Living alone or divorced & 8 & $(12.9 \%)$ \\
\hline Married or living together & 20 & $(32.3 \%)$ \\
\hline \multicolumn{3}{|l|}{ Highest educational level } \\
\hline Vocational high school & 22 & $(35.5 \%)$ \\
\hline (Technical) high school & 16 & $(25.8 \%)$ \\
\hline College/University & 24 & $(39.2 \%)$ \\
\hline \multicolumn{3}{|l|}{ Employment status } \\
\hline Student & 18 & $(29.0 \%)$ \\
\hline Blue collar worker & 22 & $(35.5 \%)$ \\
\hline White collar worker & 15 & $(24.2 \%)$ \\
\hline Other & 7 & $(11.3 \%)$ \\
\hline \multicolumn{3}{|l|}{ Primary medical diagnosis } \\
\hline Coarctation of the aorta & 16 & $(25.8 \%)$ \\
\hline Tetralogy of Fallot & 14 & $(22.6 \%)$ \\
\hline Congenital stenosis of the aortic valve & 12 & $(19.4 \%)$ \\
\hline Transposition of great vessels & 7 & $(11.3 \%)$ \\
\hline Ventricular septal defect & 5 & $(8.1 \%)$ \\
\hline Atrial septal defect & 1 & $(1.6 \%)$ \\
\hline Other & 7 & $(11.3 \%)$ \\
\hline \multicolumn{3}{|l|}{ Treatment } \\
\hline No treatment & \multicolumn{2}{|c|}{$8.2 \%$} \\
\hline Surgery & \multicolumn{2}{|c|}{$63.9 \%$} \\
\hline Catheter intervention & \multicolumn{2}{|c|}{$6.6 \%$} \\
\hline Surgery and catheter intervention & \multicolumn{2}{|c|}{$11.5 \%$} \\
\hline Surgery and drugs & \multicolumn{2}{|c|}{$8.2 \%$} \\
\hline Surgery, catheter intervention and drugs & \multicolumn{2}{|c|}{$1.6 \%$} \\
\hline \multicolumn{3}{|l|}{ Frequency of follow up } \\
\hline Every six months & \multicolumn{2}{|c|}{$3.2 \%$} \\
\hline Every year & \multicolumn{2}{|c|}{$62.9 \%$} \\
\hline Every 18 months & \multicolumn{2}{|c|}{$3.2 \%$} \\
\hline Every two years & \multicolumn{2}{|c|}{$9.7 \%$} \\
\hline Every three years & \multicolumn{2}{|c|}{$12.9 \%$} \\
\hline Every four years & \multicolumn{2}{|c|}{$1.6 \%$} \\
\hline Every five years & \multicolumn{2}{|c|}{$6.5 \%$} \\
\hline \multicolumn{3}{|l|}{ History of endocarditis } \\
\hline Yes & 2 & $(3.2 \%)$ \\
\hline No & 60 & $(96.8 \%)$ \\
\hline \multicolumn{3}{|l|}{ Responsible for the daily management of care } \\
\hline Patient & 40 & $(64.5 \%)$ \\
\hline Patient and family or GP & 22 & $(35.5 \%)$ \\
\hline
\end{tabular}

GP, general practitioner.
Table 2 Topics attributed to the four knowledge domains in congenital heart disease

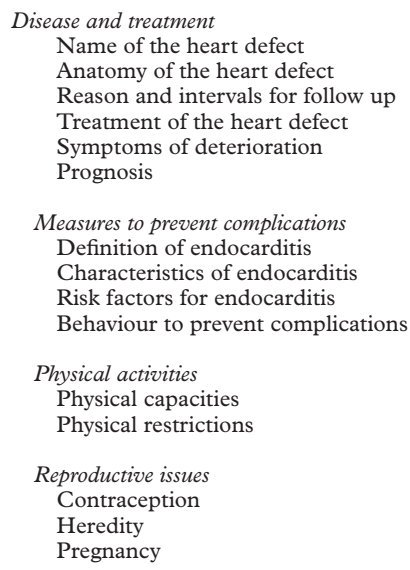

The full version of the instrument can be requested from the authors.

years $\left(Q_{1}=21 ; Q_{3}=28\right)$. This explains why most of the patients were unmarried and were still living with their parents $(54.8 \%)$. The proportion of patients with vocational high school, (technical) high school, and college/university as their highest educational level was fairly even. Approximately $60 \%$ of the patients were employed and $29 \%$ were students. The most common primary diagnoses were coarctation of the aorta (25.8\%), tetralogy of Fallot $(22.6 \%)$, and congenital stenosis of the aortic valve $(19.4 \%)$.

\section{VARIABLES AND MEASUREMENT}

Demographics and specific clinical details (methods of contraception, number of pregnancies, number of deliveries) were gathered during a patient interview. Information on the primary medical diagnosis, past and current treatment, drug regimen, and history of endocarditis was collected from the medical patient records.

Relevant aspects of patients' knowledge about congenital heart disease ${ }^{16}$ can be clustered into four domains. No existing instrument assesses all four of these domains. Available questionnaires only assess knowledge of the heart defect and its treatment or knowledge of endocarditis. ${ }^{1314}$ We therefore developed the "Leuven knowledge questionnaire for congenital heart diseases", which measures knowledge in all four domains: (1) the disease and its treatment; (2) the prevention of complications, including endocarditis; (3) physical activities; and (4) reproductive issues. This questionnaire was based in part on existing instruments. ${ }^{13} 14$ We identified 15 topics encompassing these four domains (table 2). Item generation resulted in a 33 item instrument, with 27 multiple choice questions, five multiple answer questions, and one open question. On the basis of the primary diagnosis and the patient's history and clinical status, the researchers evaluated each patient's answers as "correct," "does not know," or "incorrect." Multiple answer questions and the open question could also be scored as "incomplete." No specific scoring system was used. 
The validity of the content of the questionnaire was examined by two congenital heart disease cardiologists and one advanced clinical nurse practitioner. A pilot study was conducted in 10 patients with congenital heart disease to test their ability to read and understand the questions (face validity). In addition, two people with degrees in education evaluated the formulation of the questions and the response categories. On the basis of this expert review and remarks from the pilot study, modifications were made to the instrument.

The instrument only included items of relevance to health behaviour of patients with congenital heart disease. Other items-for example, knowledge about employability and insurability ${ }^{15}{ }^{16}$ - were not included as they do not require specific health practices to be undertaken.

Exploring the factor structure of the Leuven congenital heart disease questionnaire was not feasible owing to the limited sample size and the non-normal distribution of the variables; neither was assessment of the internal consistency of the questionnaire appropriate, as the items of the scale are not conceptually related to each other. ${ }^{17}$ For instance, knowing the name of the heart defect is not necessarily related to a knowledge of risk factors for endocarditis.

In addition to completing the Leuven congenital heart disease questionnaire, patients were asked whether they perceived the information and instruction provided by the health care professionals as sufficient, so as to evaluate their satisfaction with current educational efforts.

\section{PROCEDURE}

After patients had been seen by the congenital cardiologist for a scheduled visit at the outpatient clinic, they were asked by an independent researcher to participate in the study. After oral informed consent was obtained, information on demographic variables was collected and patients were asked whether they thought they had received enough information about their heart disease from health care professionals. Next they were instructed on how to fill out the Leuven congenital heart disease questionnaire. The researcher stayed with the patient to provide clarification if needed, and to ensure that patients filled out the questionnaire independently, without consulting accompanying persons or external sources. The data collection procedure lasted 10-15 minutes.

STATISTICAL ANALYSIS

Descriptive statistics for nominal and ordinal level data are expressed in percentages and 95\% confidence intervals, where appropriate. Medians and quartiles of continuous, nonnormally distributed variables were calculated. Univariate and multivariate analyses were performed to examine the impact of age, sex, educational level, employment status, civil state, self management, nature of the heart defect, and frequency of follow up on selected items. For univariate analyses, the Mann-Whitney U test was used for two group comparisons and the Kruskall-Wallis test for multiple group comparisons of ordinal data. Multiple logistic regression analysis (by the backward method) was used for multivariate statistics, where the knowledge variables were dichotomised as correct or incorrect answers (the latter included "incomplete," "does not know," and "incorrect" responses). The level of significance was set at $p \leqslant 0.05$.

\section{Results}

SATISFACTION WITH INFORMATION

Sixty of the 62 patients $(96.8 \%)$ were satisfied with the information provided by the congenital heart disease cardiologist treating them. Only two patients wanted more information about their disease, their previous operations, the expected disease progress, and how to deal with heart disease in daily life.

STATE OF KNOWLEDGE OF ADULT PATIENTS WITH CONGENITAL HEART DISEASE

A description in lay terms or the name of the heart defect was known by $61 \%$ of the patients (table 3), while $50 \%$ were able to locate the lesion on a diagram or describe its anatomy. The frequency of outpatient visits (97\%) and the need for regular follow up $(98 \%)$ were well understood, though the purpose of follow up - to detect any clinical deterioration-was less well known $(48 \%)$. Patients were very knowledgeable about their past treatment $(95 \%)$ and any special diet prescribed $(98.4 \%)$. Patients taking drugs $(\mathrm{n}=9 ; 15 \%)$ were apparently well informed about their drug regimen $(78 \%)$ and what to do in case of side effects $(89 \%)$. To assess knowledge about symptom management, the instrument included 11 symptoms, of which seven reflected deterioration of the heart disease requiring appropriate medical care (dizziness, shortness of breath, palpitations, chest pain, fainting, increasing fatigue, and swollen feet and legs). Between $47 \%$ and $66 \%$ of the patients answered these items correctly. Swollen feet and legs were recognised by only $16.1 \%$ of the patients as a relevant symptom. Symptoms not associated with congenital heart disease-that is, skin rash, diarrhoea, frequency of micturition, and pain on micturition-were not flagged by any patient. Thirty one per cent of the patients recognised five or more of the seven relevant symptoms; this was considered a correct answer.

Only $16 \%$ of the patients knew the definition of endocarditis, and only $8 \%$ were aware that unexplained fever for more than five days was the most typical symptom (table 4). About half the patients $(52 \%)$ knew that endocarditis could recur, and $84 \%$ were aware that they should not take antibiotics without consulting a physician. Most patients correctly identified dental abscesses $(71 \%)$ and contaminated needles $(52 \%)$ as potential risk factors for endocarditis, and knew that sexual activity was not a risk factor $(50 \%)$. It was less well known that bacteria from skin infections, body piercing and tattooing, and poor nail and skin care also contributed to the risk of endocarditis, and that smoking did not. In addition, the majority 
Table 3 Frequency distribution of patients' knowledge about the disease and its treatment

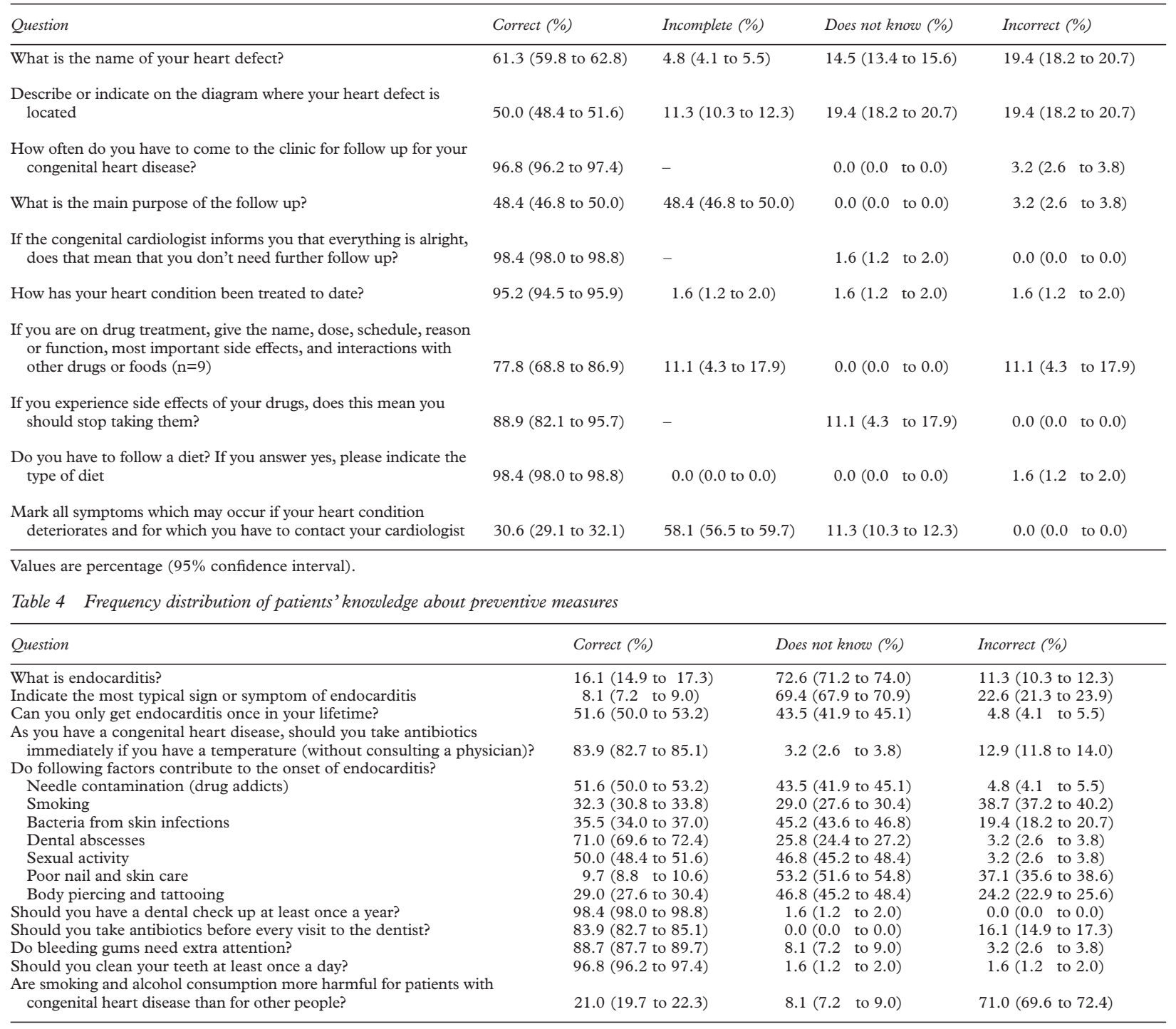

Values are percentage (95\% confidence interval),

of the patients $(71 \%)$ thought, incorrectly, that smoking and alcohol consumption were more harmful for patients with congenital heart disease than for their healthy counterparts. Knowledge about dental health practices was adequate, with more than $80 \%$ of the patients giving correct answers.

About $70 \%$ of the patients knew that they were allowed to engage in any activity that they felt capable of doing, but that competitive sports which involved daily training were prohibited (table 5). Eighty nine per cent of the patients were aware of the need to choose an occupation that is not too physically demanding, owing to the restrictions imposed by their heart disease.
Only a quarter of the patients knew correctly whether or not, and to what degree, their congenital heart disease could be inherited by their children (table 6). Eighty per cent of the female patients knew that the contraceptive pill was the most appropriate contraceptive, whereas only $27 \%$ knew whether or not an intrauterine device was contraindicated. Most women $(87 \%)$ did know whether pregnancy would cause additional risks for their health.

DETERMINANTS OF THE PATIENTS' STATE OF KNOWLEDGE

Univariate group comparisons of men and women showed that men were better able to locate their heart defect on a diagram $(57.4 \% v$

Table 5 Frequency distribution of patients' knowledge about physical activity

\begin{tabular}{|c|c|c|c|}
\hline Question & Correct (\%) & Does not know (\%) & Incorrect (\%) \\
\hline $\begin{array}{l}\text { May you engage in all physical activity of which you feel you } \\
\text { are capable? }\end{array}$ & $69.4(67.9$ to 70.9$)$ & $1.6(1.2$ to 2.0$)$ & $29.0(27.6$ to 30.4$)$ \\
\hline Can you take part in competitive sports, requiring daily training? & $71.0(69.6$ to 72.4$)$ & $8.1(7.2$ to 9.0$)$ & 21.0 (19.7 to 22.3$)$ \\
\hline $\begin{array}{l}\text { Should you choose an occupation that is not too physically } \\
\text { demanding as you should be careful not to overexert yourself? }\end{array}$ & $88.7(87.7$ to 89.7$)$ & $6.5(5.7$ to 7.3$)$ & $4.8(4.1$ to 5.5$)$ \\
\hline
\end{tabular}

Values are percentage (95\% confidence interval). 
Table 6 Frequency distribution of patients' knowledge about reproductive issues

\begin{tabular}{|c|c|c|c|}
\hline Question & Correct (\%) & Does not know (\%) & Incorrect (\%) \\
\hline $\begin{array}{l}\text { What is the chance that your children will have congenital } \\
\text { heart disease? }\end{array}$ & $25.8(24.4$ to 27.2$)$ & $32.3(30.8$ to 33.8$)$ & $41.9(40.3$ to 43.5$)$ \\
\hline \multicolumn{4}{|l|}{$\begin{array}{l}\text { Which contraceptives are the most advisable for you to use in } \\
\text { the light of your congenital heart disease? (only for women): }\end{array}$} \\
\hline Contraceptive pill & $80.0(74.8$ to 85.2$)$ & 20.0 (14.8 to 25.2$)$ & $0.0(0.0$ to 0.0$)$ \\
\hline Intrauterine device & 26.7 (20.9 to 32.5$)$ & $53.3(46.8$ to 59.8$)$ & $20.0(14.8$ to 25.2$)$ \\
\hline $\begin{array}{l}\text { Are you at risk of deterioration during pregnancy? (only for } \\
\text { women) }\end{array}$ & $86.7(82.3$ to 91.1$)$ & $0.0(0.0$ to 0.0$)$ & 13.3 ( 8.9 to 17.7 ) \\
\hline
\end{tabular}

Values are percentage (95\% confidence interval).

$26.7 \%$; $=230.5 ; \mathrm{p}=0.031$ ), and were more knowledgeable about physical activities $(76.6 \%$ $v 46.7 \%$; $\mathrm{U}=243.0 ; \mathrm{p}=0.025)$ and competitive sports $(78.7 \%$ v $46.7 \%$; $\quad(\mathrm{U}=228.5$; $p=0.01)$. A greater proportion of patients who managed their disease themselves knew the definition of endocarditis $(22.5 \%)$ than patients who were assisted by family members or a general practitioner $(4.5 \%$; $U=278.5$; $\mathrm{p}=0.002)$. A significant difference in knowledge about the localisation of the heart defect was found between the diagnostic categories $\left(\chi^{2}=20.276 ; \mathrm{df}=3 ; \mathrm{p}<0.001\right)$. Eighty one per cent of the patients with coarctation of the aorta and $50 \%$ of the patients with aortic valve stenosis were able to locate their defect correctly on a diagram - far more than the patients with tetralogy of Fallot (7\%). Finally, patients with a college or university degree knew more about the physical restrictions involved with congenital heart disease $(87.5 \%)$ than those with technical high school $(62.5 \%)$ or vocational high school $(54.5 \%)$ level education $\left(\chi^{2}=8.480 ; \mathrm{df}=3 ; \mathrm{p}=0.037\right)$.

Multiple logistic regression showed that the answers to only four of the questionnaire items could be explained by clinical or demographic variables. These were the ability to locate the heart defect on a diagram, sexual activity not being a risk factor for endocarditis, physical restrictions, and competitive sports. Table 7 summarises the multivariate models obtained. The results showed that the correct location of the heart defect was determined by the primary diagnosis of the malformation. In particular, fewer patients with tetralogy of Fallot gave correct answers. In comparison with students, blue collar workers and more highly educated patients were more likely to know that sexual activity involved no risk of endocarditis. Knowledge about physical restrictions was highly correlated with knowledge about competitive sports, and both were greater in male patients. The explained variance of these models varied from $11.4 \%$ to $36 \%$.

\section{Discussion}

Patient's knowledge of their disease has been considered a prime factor in achieving adequate health behaviour. ${ }^{3}$ In this study we have assessed how much adult patients with congenital heart disease know about their heart defect, its previous and current treatment, and the measures necessary to prevent complications. Our findings indicate that on the whole the patients were very knowledgeable (more than $80 \%$ giving correct answers) about treatment, frequency of follow up, dental practices, vocational choices, the contraceptive pill as an appropriate form of contraception, and the risks of pregnancy for women. They were less knowledgeable (50-80\% giving correct answers) about the name and anatomy of the lesion, the fact that endocarditis could recur, and the appropriateness of physical activities. There was poor understanding (less than 50\% giving correct answers) about the purpose of follow up, the symptoms of deterioration, the definition, typical signs, and risk factors of endocarditis, the impact of smoking and alcohol consumption on congenital heart disease, inheritance of the malformation, and the appropriateness of an intrauterine device as a method of contraception.

This study expands the previous research on adults with congenital heart disease, ${ }^{11-14}$ as it assesses the relevant knowledge domains more comprehensively and also examines determinants of knowledge using multivariate statistics. When comparing our results with previous findings it was apparent that, though comparable numbers of patients in our study and in others ${ }^{12}{ }^{13} \mathrm{knew}$ the name of their heart disease, in our study twice as many patients as in a previous study ${ }^{13}$ were able to locate the anatomy of the malformations on a diagram. Congenital

Table 7 Determination of factors concerned with knowledge of adult patients about their congenital heart disease, based on multiple logistic regression analysis

\begin{tabular}{|c|c|c|c|c|c|}
\hline Dependent variable & Covariates & Odds ratio & $95 \% C I$ & $p$ Value & Nagelkerke $R^{2}$ \\
\hline Localisation of the heart defect & $\begin{array}{l}\text { Coarctation of the aorta versus aortic valve stenosis } \\
\text { Tetralogy of Fallot versus aortic valve stenosis } \\
\text { Other diagnostic groups versus aortic valve stenosis }\end{array}$ & $\begin{array}{l}3.611 \\
0.064 \\
1.019\end{array}$ & $\begin{array}{l}0.612 \text { to } 20.320 \\
0.0061 \text { to } 0.676 \\
0.232 \text { to } 4.466\end{array}$ & $\begin{array}{l}0.145 \\
0.022 \\
0.981\end{array}$ & 0.360 \\
\hline $\begin{array}{l}\text { Sexual activity as no risk factor for } \\
\text { endocarditis }\end{array}$ & $\begin{array}{l}\text { Educational level } \\
\text { White collar worker versus blue collar worker } \\
\text { Student versus blue collar worker } \\
\text { Others versus blue collar worker }\end{array}$ & $\begin{array}{l}2.741 \\
0.935 \\
0.078 \\
0.113\end{array}$ & $\begin{array}{l}1.187 \text { to } 6.325 \\
0.207 \text { to } 4.234 \\
0.009 \text { to } 0.677 \\
0.010 \text { to } 1.328\end{array}$ & $\begin{array}{l}0.018 \\
0.931 \\
0.021 \\
0.083\end{array}$ & 0.248 \\
\hline Physical restrictions & Female sex & 0.243 & 0.071 to 0.834 & 0.025 & 0.114 \\
\hline Competitive sports & Female sex & 0.243 & 0.071 to 0.834 & 0.025 & 0.114 \\
\hline
\end{tabular}

CI, Confidence interval. 
heart disease cardiologists at our centre often make drawings of the heart for educational purposes, which could explain this difference. Compared with previous research, our patients were less knowledgeable about their prescribed drug treatment. ${ }^{14}$ This is explicable by the very stringent criteria we used to judge the answer as correct. Patients needed to know the name, dose, schedule, reason or function, most common side effects, and relevant interactions with other drugs and foods. In the light of this, the result obtained is considered good. As in previous reports, knowledge about the definition and risk factors for endocarditis was insufficient in our sample. ${ }^{12-14}$ However, knowledge about dental practices and the need for antibiotics with dental procedures was good, a finding shared with other studies. The relatively good understanding about the heart defect, treatment, and preventive measures in this sample is likely to be explained by sustained educational efforts made by our congenital cardiologists.

\section{DETERMINANTS OF THE PATIENTS' STATE OF} KNOWLEDGE

Multivariate analyses showed that the correct location of the heart defect on a diagram was determined by the complexity of the lesion. Patients with tetralogy of Fallot, which is difficult to draw or describe, had problems in locating their defect. Men were more aware than women of the necessary physical restrictions and the prohibition of competitive sports. Clinical experience suggests that during outpatient visits sports issues are more often discussed with men than with women, because men in our patient population tend to perceive physical activities as a more important part of their life. Finally, we found that awareness of sexual activity as a risk factor for endocarditis was determined by educational level and employment status, for which no explanation has been found. The limited degree to which the logistic regression models explained the variance of the replies was expected. Arguably, knowledge and learning are multifactorial constructs that are determined by much more than merely demographic or clinical variables. ${ }^{18}$

In our sample of adults, age was not found to be a determinant of knowledge. However, a recent study ${ }^{10}$ showed that children and adolescents have a very poor understanding of illness, though their knowledge seems to improve by increasing age.

\section{CLINICAL IMPLICATIONS}

Our patients' poor knowledge about particular aspects of the disease, treatment, or preventive measures is a problem and may have major consequences. For instance, patients must be knowledgeable about the risk factors for endocarditis and how they can avoid potential exposure, as well as about symptoms of deterioration of their heart condition.

The finding that $20-30 \%$ of our patients do not know whether or not physical activities are contraindicated may result in harmful behaviour or inappropriate restrictions, which in turn compromise the social integration of the patient. Also a sound understanding of the purpose of follow up is imperative, in order to motivate the patients to comply with the scheduled outpatient visits. This emphasises the importance of good patient education. Even in benign heart defects, health care professionals need to explain the nature and progression of the disease in detail, as simply telling patients they are doing well results in stressful misunderstandings. ${ }^{19}$

The results of this study have relevance for daily clinical practice. Though our patients were very satisfied with the information provided, our findings suggest that there are important knowledge gaps. Educational efforts should be an integral part of follow up, in order to enhance patients' understanding of the different aspects of their heart condition and what management strategies are appropriate to achieve the best outcome. ${ }^{1314}{ }^{20}$ In this respect, structured and repetitive educational interventions are needed. It is therefore advised that programmes for adult patients with congenital heart disease should be interdisciplinary. ${ }^{152122}$ We have recently employed an advanced clinical nurse practitioner in congenital heart disease who has developed a structured education programme based on the identified knowledge gaps in our patient population.

\section{METHODOLOGICAL ISSUES}

The lack of an appropriate and established instrument to measure how knowledgeable congenital heart disease patients were in relevant health behaviour domains resulted in our developing the Leuven knowledge questionnaire for congenital heart diseases. Key psychometric properties of the questionnaire were assessed by expert review and in a pilot study, and these suggested a good content and face validity. However, on the basis of the current analyses, the relevance of some of the items could be questioned. Therefore, further testing of the validity and reliability of the questionnaire is needed.

In this study the questionnaire was self administered in presence of the researcher. This resulted in a low attrition rate, no missing data, and ensured that the questionnaire was independently filled out by the patient. However, a disadvantage of this approach was the limited size of the sample that could be studied. The study should be replicated using a larger sample size.

The fact that patients participated in the study after they had been seen by the cardiologist could be a source of bias because of possible "refreshment effects." Although the cardiologist was not blinded to the study, no particular modifications in educational approach were observed during the study period.

\section{CONCLUSIONS}

In this study we assessed how knowledgeable adult patients with congenital heart disease were about their disease, its treatment, and measures to prevent complications. Although some aspects were well understood, the results showed that there are still significant gaps in knowledge in this patient group. Because this 
lack of knowledge may have harmful consequences, centres caring for adults with congenital heart disease should invest in adequate and structured patient education in order to improve the outcome in this population.

We gratefully thank Ruth Harris for the valuable remarks and comments on an earlier version of this paper.

1 Perloff JK. Residua and sequelae: a perspective. In: Perloff JK, Child JS, eds. Congenital heart disease in adults. Philadelphia: WB Saunders, 1998:303-15.

2 Somerville J. Management of adults with congenital heart disease: an increasing problem. Anпи Rev Med 1997;48: $283-93$.

3 Gochman D. Handbook of health behavior research, vol 1 . New York: Plenum Press, 1997.

4 Saunders CP, Roberts GJ. Dental attitudes, knowledge, and health practices of parents of children with congenital heart health practices of parents of children with
disease. Arch Dis Child 1997;76:539-40.

5 Perez-Piaya Moreno MR, de Diego Fernandez P, Chinchilla Molina JM, et al. Profilaxis de endocarditis bacteriana en ninos con cardiopatia congenita: estado actual de conocimientos por parte de los padres. [Prophylaxis of bacterial endocarditis in children with congenital heart disease: current status of parents' knowledge]. An Esp Pediatr 1997;47 389-91.

6 Cetta F, Bell TJ, Podlecki DD, et al. Parental knowledge of bacterial endocarditis prophylaxis. Pediatr Cardiol 1993;14: 220-2.

7 Kaden GG, McCarter RJ, Johnson SF, et al. Physicianpatient communication: understanding congenital heart disease. Am 7 Dis Child 1985;139:995-9.

8 Sholler GF, Celermajer JM Prophylaxis of bacterial endocarditis. Awareness of need. Med f Aust 1984;140: $650-2$

9 Cetta F, Podlecki DC, Bell TJ. Adolescent knowledge of bacterial endocarditis prophylaxis. F Adolesc Health 1993; $14 \cdot 540-2$
10 Veldtman GR, Matley SL, Kendall L, et al. Illness ldtman GR, Matley SL, Kendall L, et al. Ilness disease. Heart 2000;84:395-7.

11 Vogel M, Knirsch W, Lange PE. Schwere komplikationen durch nichtbeachtung der endokarditisprophylaxe wahrend zahnarztlicher eingriffe bei erwachsenen mit angeborenen herzfehlern. [Severe complications caused by inattention to endocarditis prevention during dental procedures in adults with congenital heart abnormalities]. Dtsch Med Wochenschr 2000;125:344-7.

12 Cetta F, Graham LC, Lichtenberg RC, et al. Piercing and tattooing in patients with congenital heart disease: patient and physician perspective. $\mathcal{F}$ Adolesc Health 1999;24:160-2.

13 Kantoch MJ, Collins-Nakai RL, Medwid SM, et al. Adult patients' knowledge about their congenital heart disease. Can F Cardiol 1997;13:641-5.

14 Cetta F, Warnes CA. Adults with congenital heart disease: patient knowledge of endocarditis prophylaxis. Mayo Clin Proc 1995;70:50-4.

15 Warnes CA. Establishing an adult congenital heart disease clinic. Am f Card Imaging 1995;9:11-14.

16 Day MJ. Educational assessment of the adult with congenital heart disease. Nurs Clin North Am 1994;29:299-318.

17 Strickland OL. When is internal consistency reliability assessment inappropriate? f Nurs Meas 1999;7:3-4.

18 Redman BK. The practice of patient education, 8th ed. St Louis: CV Mosby, 1997

19 Manning JA. Congenital heart disease and the quality of life. In: Engle MA, Perloff JK, eds. Congenital heart disease after surgery: benefits, residua, sequelae. New York: Yorke Medical Books, 1983:347-61.

20 Pitcher DW, Papouchado M, Channer KS, et al. Endocarditis prophylaxis: do patients remember advice and know what to do? BMF 1986;293:1539-40.

21 Perloff JK, Miner PD. Specialized facilities for the comprehensive care of adults with congenital heart disease. In: Perloff JK, Child JS, eds. Congenital heart disease in adults. Philadelphia: WB Saunders, 1998:9-12.

22 Canobbio M, Day MJ. The role of the clinical nurse specialist in an adult congenital heart disease program. Nurs Clin North Am 1994:29:357-66.

\section{IMAGES IN CARDIOLOGY}

\section{Superior vena cava syndrome caused by multiple pacing leads}

A 55 year old man complained of signs and symptoms typical of the superior vena cava (SVC) syndrome. In 1977 he underwent surgical implantation of an AAI mode permanent pacemaker through the left subclavian approach for sick sinus syndrome (type I). Because of the repeated pacing lead breakage, VVI mode pacemakers were implanted through the right subclavian approach in 1985 and 1999. Two months after the last operation, he noticed his face was progressively swelling.
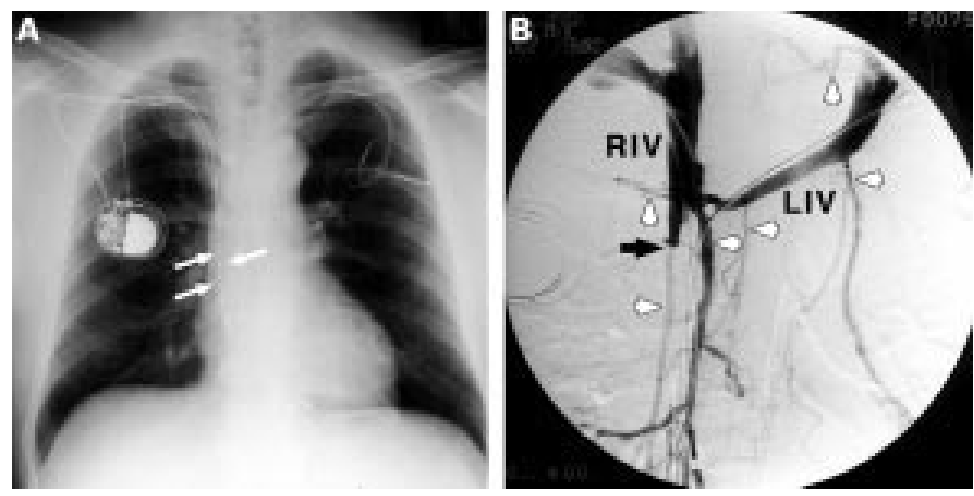

A chest $x$ ray showed that the three pacemaker wires (arrows) were entangled with one another in the SVC (panel A). The right internal jugular venogram revealed that the SVC was occluded at the site (arrow) just caudal to the bifurcation of the inominate veins (RIV, right inominate vein; LIV, left inominate vein) and well developed collateral veins (arrowheads) from the inominate veins were observed returning to the inferior vena caval and azygos systems (panel B). Simultaneous venograms from the right internal jugular vein and the right atrium revealed that the SVC obstruction was found at the portion where the pacing leads were entangled. It was suggested that the entangled leads caused the venous flow stagnation, resulting in the thrombotic SVC occlusion. Attention has to be given to the development of the SVC syndrome as a possible complication of multiple pacing lead implantation.

H KAI

T HONMA T IMAIZUMI naikai@med.kurume-u.ac.jp 